Jurnal Pemberdayaan: Publikasi Hasil Pengabdian kepada Masyarakat

Vol. 2, No. 2, Agustus 2018, Hal. 347-352

ISSN: 2088 4559; e-ISSN: XXXX-XXXX

DOI:

\title{
PEMANFAATAN LAHAN KOSONG SEBAGAI TANAMAN OBAT KELUARGA WARGA PRANCAK DUKUH PANGGUNGHARJO, SEWON, BANTUL, YOGYAKARTA
}

\author{
Dholina Inang Pambudi ${ }^{1}$ dan Rizqi Yudha Erlangga ${ }^{2}$ \\ ${ }^{1,2}$ Universitas Ahmad Dahlan Yogyakarta \\ Email: dholina.pambudi@pgsd.uad.a.c.id
}

\begin{abstract}
ABSTRAK
Salah satu permasalahan yang dijumpai di Desa Prancak Dukuh RT 03 dan RT 04 adalah kurangnya pemanfaatan lahan kosong yang ada di sekitar sebagai lahan hijau. Berdasar hal tersebut program Kuliah Kerja Nyata (KKN) Universitas Ahmad Dahlan (UAD) kali ini difokuskan pada program yang mendukung kegiatan berwawasan lingkungan. Program ini bertujuan memanfaatkan lahan pekarangan warga yang kosong menjadi lebih berdaya guna dalam mewujudkan lingkungan sehat dan hijau. Metode pelaksanaan program KKN meliputi penyuluhan, dan praktik langsung. Dampak dari kegiatan KKN ini adalah : 1) Terciptanya kesadaran masyarakat akan lingkungan sehat dan hijau, 2) Peningkatan pengetahuan masyarakat untuk memanfaatkan lahan pekarangan yang tidak terpakai sebagai lahan tanaman obat keluarga (TOGA).
\end{abstract}

Kata kunci : Pemanfaatan, TOGA, lahan kosong

\section{ABSTRACT}

One of the problems encountered in Prancak Dukuh RT 03 and RT 04 was the lack of utilization of the surrounding land as green land. So the Alternative KKN VI.B.2 program is focused on programs that support environmentally sound activities. This program aims to utilize vacant community land to become more efficient in realizing a green environment. The methods for implementing the KKN program include counseling, and direct practice. The impacts of the KKN activities are: 1) The creation of public awareness of the green environment, 2) Increasing the knowledge of the community to utilize unused land as a family medicinal plant (TOGA).

Keywords: Utilization, Prancak Dukuh, Family Medicinal Plants (TOGA) 


\section{PENDAHULUAN}

Desa Prancak Dukuh terletak di Jalan Parangtritis Km 6,5 di Kelurahan Panggungharjo, Kecamatan Sewon. Berdasarkan hasil wawancara dengan salah satu tokoh masyarakat Dusun Prancak Dukuh sebagian besar mata pencaharian warga sebagai petani dan juga pedagang. Terdapat beberapa permasalahan yang ditemukan di Desa Prancak Dukuh khususnya antara lain: 1) Banyak lahan perkarangan warga yang kosong atau kurang dimanfaatkan menjadi lahan hijau, 2) Kurangnya pengetahuan masyarakat dalam memanfaatkan lahan kosong.

Pemanfaatan lahan kosong digunakan agar lahan yang terbengkalai atau kosong dapat dimanfaatkan menjadi lahan menanam tanaman yang bermanfaat dan memiliki nilai jual. Dalam program kerja bidang tematik ini kelompok KKN dari UAD melihat potensi lahan kosong di sekitar lingkungan warga yang dapat dimanfaatkan ditanami TOGA seperti sambiloto, daun dewa, kunyit, dsbnya. Pemberdayaan masyarakat dalam mengelola lahan kosong menjadi lahan hijau menggunakan sistem pertanian organik yang mengedepankan ramah lingkungan dan yang pasti baik untuk kesehatan. Untuk pemanfaatan lahan kosong atau sempit dapat dilakukan dengan berbagai cara antara lain dengan memakai media polybag, hidrogel, maupun hidroponik. Pemanfaatan pekarangan sebagai sarana budidaya tanaman obat telah dikenal dalam konsep Tanaman Obat Keluarga (TOGA), yaitu tanaman hasil budidaya rumahan yang berkhasiat sebagai obat bagi keluarga.

Pada hakekatnya, TOGA adalah sebidang tanah, baik di halaman rumah, kebun, atau ladang yang digunakan untuk membudidayakan tanaman berkhasiat obat. Tujuannya untuk memenuhi kebutuhan obat-obatan keluarga. Istilah TOGA dikembangkan untuk mengganti istilah Apotek Hidup yang telah ada sebelumnya (Agromedia, 2007).

Upaya pengobatan dengan obat-obat tradisonal merupakan salah satu bentuk peran serta masyarakat dan sekaligus merupakan teknologi tepat guna yang potensial untuk menunjang pembangunan kesehatan (Tukiman, 2004). Dengan adanya TOGA warga Prancak Glondong dapat memanfaatkan lahan dan mengetahui manfaat dari tanaman-tanaman yang bermanfaat sebagai obat untuk penyakit-penyakit tertentu. Peran serta warga Prancak Glondong dalam pengelolaan lingkungan hijau merupakan kesediaan warga untuk membantu berhasilnya program pemanfaatan lingkungan hijau sesuai dengan kemampuan setiap orang tanpa mengorbankan kepentingan diri sendiri. 


\section{METODE}

Untuk mencapai tujuan yang diharapkan, program KKN UAD di Desa Prancak Dukuh dilakukan dengan memanfaatkan lahan kosong dengan membuat TOGA melalui penyuluhan kepada masyarakat dan praktek langsung. Ringkasan metode pelaksanaan beserta jam kerja efektif mahasiswa (JKEM) tersaji pada Tabel 1.

Tabel 1 . Metode, Kegiatan, JKEM dan mahasiswa yang terlibat

\begin{tabular}{llcc}
\hline \multicolumn{1}{c}{ Metode } & \multicolumn{1}{c}{ Kegiatan } & JKEM & $\begin{array}{c}\text { Jumlah } \\
\text { mahasiswa yang } \\
\text { terlibat }\end{array}$ \\
\hline Penyuluhan dan & Persiapan tanaman TOGA & $1 \times 100 "$ & 27 \\
Praktek & Persiapan lahan & $2 \times 100 "$ & 27 \\
& Penanaman bibit dan tanaman & $1 \times 100 "$ & 27 \\
& Pemeliharaan tanaman & $4 \times 100 "$ & 27 \\
\hline
\end{tabular}

Berikut tahapan kegiatan KKN di Desa Prancak Dukuh dalam memanfaatkan lahan kosong dengan membuat TOGA :

1. Persiapan tanaman Toga

Pada tahap ini mahasiswa KKN mendiskusikan dan memilah-milih tanaman obat yang cocok bagi kesehatan dan berguna bagi warga Prancak Dukuh.

2. Persiapan lahan

Lahan kosong yang akan dipersiapkan untuk tanaman Toga dibersihkan dari rumput untuk selanjutnya dibuat gembur untuk siap sebagai media tanam.

3. Penanaman bibit dan tanaman

Bibit dan tanaman yang sudah disemai siap ditanam pada media tanah maupun polybag

4. Pemeliharaan tanaman

Dalam hal pemeliharaan ini yang dimaksud adalah penyiraman dan pengontrolan tanaman. Hal ini dilakukan secara berkala agar menghasilkan tanaman obat yang subur dan bermanfaat bagi warga. 


\section{HASIL, PEMBAHASAN, DAN DAMPAK}

Hasil dari program ini adalah terwujudnya TOGA pada lahan kosong yang tidak terpakai di sekitar rumah warga Prancak Dukuh. Selain itu semakin meningkatnya kesadaran warga terkait pemanfaatan lahan kosong sebagai lahan hijau yang lebih memiliki daya guna dan nilai jual bagi warga. Berikut beberapa jenis tanaman dan khasiatnya yang sudah ditanam oleh warga Prancak Dukuh tersaji pada Tabel 2.

Tabel 2. Tanaman obat yang telah berhasil ditanam oleh warga Prancak Dukuh

\begin{tabular}{|c|c|}
\hline Nama Tanaman & Khasiat \\
\hline Sambang darah & Disentri, muntah batuk darah, pendarahan dan penyakit kulit \\
\hline Sambung nyawa & Mengobati gigitan ular, pendarahan, batu darah, diabetes \\
\hline Sambiloto & Demam, tifus, nyeri, asam urat, dan sakit gigi \\
\hline Daun salam & Megobati saluran pencernaan, darah tinggi, dan tukak lambung \\
\hline Daun dewa & Kutil, pendarahan, dan gigitan ular \\
\hline Prasman & Peluruh kencing, borok, sakit kepala, dan panas dalam \\
\hline Pecut kuda & Radang tenggorokan, batuk, keputihan, rematik, dan hepatitis A \\
\hline Sri gading & $\begin{array}{l}\text { Obat peradangan, penurun panas, anti oksidan, dan mengeluarkan } \\
\text { cacing dari tubuh }\end{array}$ \\
\hline Dadang gendis & $\begin{array}{l}\text { Untuk mengobati disentri, kencing manis, dan susah buang air } \\
\text { kecil }\end{array}$ \\
\hline Daun mangkokan & Mengatasi permasalahan rambut \\
\hline Sirih merah & $\begin{array}{l}\text { Menghentikan mimisan, tukak lambung, luka bakar, dan } \\
\text { hipertensi }\end{array}$ \\
\hline $\begin{array}{l}\text { Daun ungu } \\
\text { henduleum }\end{array}$ & $\begin{array}{l}\text { Wasir atau ambien, batu empedu, konstipasi, bisul, rematik, } \\
\text { encok, demam, dan pendarahan }\end{array}$ \\
\hline
\end{tabular}




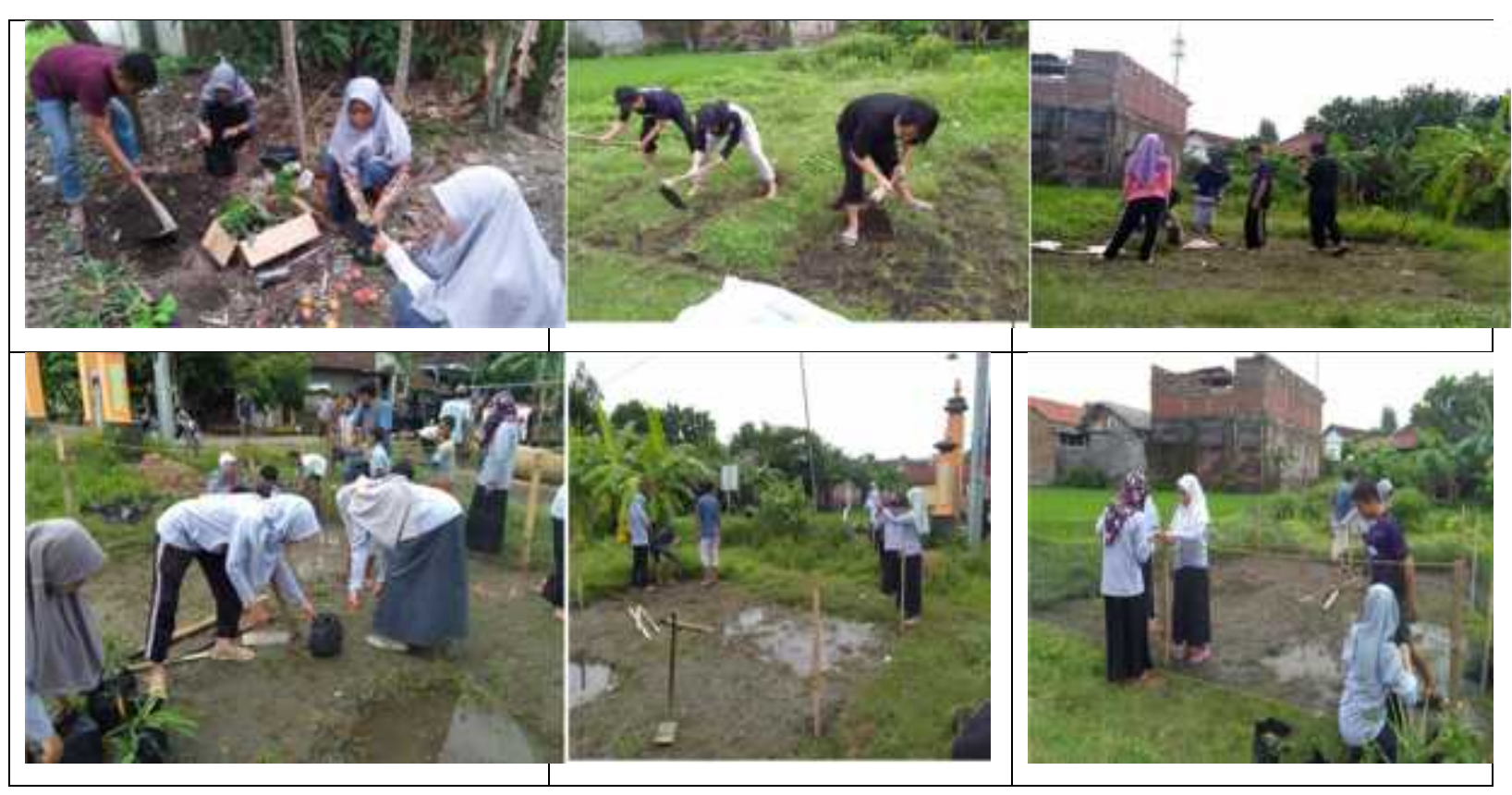

Gambar 1. Aktivitas mahasiswa KKN UAD dalam program lingkungan hijau

Dari Gambar 1 terlihat program KKN di Desa Prancak Dukuh dapat terlaksana dengan partisipasi yang cukup tinggi dengan kata lain dapat memanfaatkan lahan kosong dengan membuat taman obat keluarga dalam program-program yang telah direncanakan. Dampak dari kegiatan KKN ini adalah : 1) Terciptanya kesadaran masyarakat akan lingkungan hijau, 2) Peningkatan pengetahuan masyarakat untuk memanfaatkan lahan perkarangan dalam penanaman Toga.

\section{SIMPULAN}

Berdasarkan pelaksanaan kegiatan yang telah dilakukan dapat disimpulkan bahwa: (1) Masyarakat Desa Prancak Dukuh sadar dengan lingkungan hijau (2) Masyarakat mendapatkan pengetahuan baru dari pemanfaatan lahan yang kosong digunakan untuk TOGA. Pemahaman dan perubahan perilaku dimaksud masih perlu terus ditingkatkan sehingga pemanfaatan lahan pekarangan menjadi lebih produktif dan bernilai ekonomis.

\section{DAFTAR PUSTAKA}

Agromedia, R. (2007). Memanfaatkan Pekarangan untuk Taman Obat Keluarga. AgroMedia.

Tukiman. (2004). Pemanfaatan Tanaman Obat Keluarga (TOGA) untuk kesehatan keluarga.

USU digital library, 1. 
